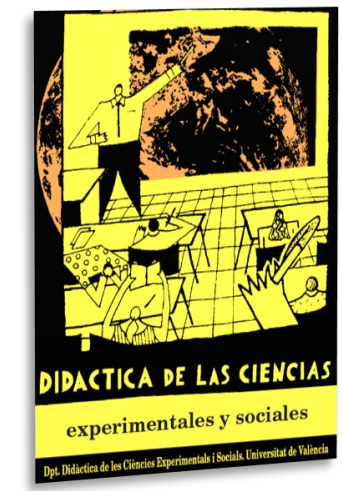

\title{
La fotografía como fuente histórica en el aula. Análisis de una metodología para la enseñanza de la Historia en la Educación Superior
}

\author{
Photography as a historical source in the \\ classroom. Assessment of a methodology \\ for teaching History in Higher Education
}

DOI: $10.7203 / D C E S .39 .16078$

\author{
Santiago Ponsoda López de Atalaya \\ Universitat d'Alacant/Universidad de Alicante, santiago.ponsoda@ua.es \\ ORCID iD: https://orcid.org/0000-0001-8945-5199 \\ Rubén Blanes Mora \\ Universitat d'Alacant/Universidad de Alicante, ruben.blanes@ua.es
}

\begin{abstract}
RESUMEN: El presente artículo analiza una metodología activa centrada en el uso de fuentes históricas, en este caso la fotografía, para la enseñanza de la Historia en la Educación Superior. La propuesta analizada se llevó a cabo en la asignatura Didáctica de las Ciencias Sociales: Historia del Grado de Maestro en Educación Primaria de la Universidad de Alicante. Los datos obtenidos han sido tratados de forma cualitativa y han permitido conocer, además, la percepción del alumnado ante una nueva manera de trabajar contenidos históricos. Los resultados obtenidos confirman que la metodología que utiliza de forma adecuada la fotografía como fuente histórica incentiva el análisis y la reflexión sobre los hechos tratados y, al mismo tiempo, se convierte en un elemento motivador para la enseñanza de la Historia.
\end{abstract}

Palabras Clave: Didáctica de la Historia, fotografía, fuentes primarias, Educación Superior, metodologías.

ABSTRACT: This work analyses an active methodology focused on the use of historical sources, in this case, photography, for the teaching of History in Higher Education. The assessed proposal was carried out in the Didactic of the Social Sciences: History subject of the Degree in Primary Education of the University of Alicante. The data obtained have been analysed from a qualitative approach and have provided information on the students' perception of a new way of working with historical contents. The results highlight that the methodology that adequately uses photography as a historical source encourages reflection and analysis on the facts dealt with and, at the same time, becomes a motivating element for the teaching of History.

KEYWORDS: History didactics, photography, primary sources, Higher Education, methodologies.

Fecha de recepción: enero de 2020

Fecha de aceptación: mayo de 2020 


\section{INTRODUCCIÓN}

Tradicionalmente la enseñanza de la Historia se ha basado en el uso de una metodología expositiva y memorística. Este hecho ha incidido, sin duda, en la percepción que el alumnado tiene sobre esta materia de forma negativa (Fuentes, 2003). Frente a esta situación, de un tiempo a esta parte, se ha incidido en la necesidad de un cambio metodológico que se centre, no tanto en el estudio y memorización de fechas, personajes y eventos, si no en un proceso de enseñanza-aprendizaje de la materia que conduzca a lo que se conoce como alfabetización histórica o desarrollo del pensamiento histórico. Entendido este último concepto, en palabras de Saiz (2013), como la formación histórica para entender y explicar la realidad acudiendo a la temporalidad o, según Seixas y Morton (2013), como el procedimiento que sigue la ciencia histórica para interpretar las fuentes del pasado.

Pero para conseguir este propósito diversos autores señalan que el proceso de enseñanzaaprendizaje de la historia se ha de encaminar hacia el conocimiento del método histórico propio de la ciencia (Prats y Santacana, 2015; Gómez, Ortuño y Molina 2014; Prieto, Gómez y Carrasco, 2013; Prats 2007; Hernández, 2002; Wineburg, 2001;). A pesar de ello, durante muchos años se ha considerado que esta línea era inviable a causa de la incapacidad del alumnado de primaria para comprender conceptos abstractos (Hernández y Cardona, 2015). Frente a esta concepción, Calvani (1999) afirma que los problemas del aprendizaje de la Historia en estas edades no derivan tanto de las incapacidades de los niños y niñas, sino de los contenidos elegidos, la metodología didáctica y el tratamiento de estos.

La aproximación al método histórico, al quehacer del historiador, coincide con una de las tres formas de enseñar historia enunciadas por Peck y Seixas (2008), la cual focaliza la enseñanza y la comprensión de la Historia en su mismo método, mediante la investigación, para conseguir que el alumnado se forme en el pensamiento y la reflexión. Una concepción de la enseñanza de la historia que contribuirá a formar al alumnado en el pensamiento histórico (Gómez et al., 2014) y que se encuentra estrechamente vinculada a los conceptos metodológicos comúnmente aceptados por los investigadores (Sáiz y Domínguez, 2017) como son: la utilización de fuentes para conseguir pruebas o evidencias, la explicación de causas y consecuencias, la empatía y el tiempo histórico, entendido este último como cambio y continuidad.

Por tanto en el desarrollo del pensamiento histórico del alumnado, así como en su aproximación al método histórico, podemos señalar que el trabajo con fuentes históricas, primarias o secundarias, ocupa un lugar destacado en un proceso de enseñanza-aprendizaje en el que el profesorado es el responsable de guiar al alumnado en su introducción a la metodología científica de la disciplina y en el tratamiento adecuado de las fuentes, pues cómo señalan diversos autores la interpretación de la Historia a partir de las fuentes se trata de uno de los aspectos fundamentales en la formación del pensamiento histórico (Santisteban, González-Monfort y Pagès, 2010; Santisteban, 2010).

Dicho esto, se nos revela como fundamental la preparación del futuro profesorado en este sentido, ya que en general ambos aspectos, fuentes y método historiográfico, son ajenos para los futuros maestros y maestras. De hecho, en la mayoría de los casos su relación con estos aspectos ha sido escasa, por no decir nula, en su formación previa. Esta realidad ha sido puesta de manifiesto en una investigación sobre la evaluación en la educación obligatoria, en la cual se comprueba que el uso de fuentes y evidencias para analizar el pasado y construir un discurso es prácticamente inexistente durante su etapa de formación obligatoria (Miralles, Gómez y Monteagudo, 2012). Si bien esta afirmación requeriría una investigación más exhaustiva que mostrará la realidad en lo que se refiere al trabajo con fuentes y a través del método científico durante la formación previa a los estudios universitarios. Ello permitiría conocer el grado de familiaridad del alumnado con esta manera de trabajar la materia, para de este modo poder ajustar los programas formativos de las asignaturas relacionadas con la didáctica de la historia en los grados universitarios que se encargan de formar al futuro profesorado. No obstante, en los últimos años, son diversos los trabajos que muestran experiencias didácticas, tanto en la educación superior como en otras etapas previas, en relación al 
tratamiento didáctico de las fuentes históricas para la enseñanza de la historia, a la aproximación al método científico y al desarrollo del pensamiento histórico (Llonch-Molina y Parisi-Moreno, 2018; Inarejos, 2017; Egea y Arias 2015; Prieto et al., 2013; Feliu y Sallés 2011).

Así pues, para poder desarrollar el pensamiento histórico entre el alumnado, se ha de formar al profesorado con el propósito de que sea capaz de dominar los procedimientos metodológicos que permitan la adquisición de habilidades cognitivas propias de la materia y la comprensión de los límites de la narrativa histórica. Entendiendo por habilidades, en este caso, la argumentación y la interpretación a partir del trabajo con fuentes históricas (Ortega, Carcedo y Blanco, 2018). En esta línea, el correcto tratamiento de estas fuentes generaría una serie de destrezas básicas entre el alumnado como son, en primer lugar, el planteamiento de problemas de aprendizaje histórico a través de la presentación del pasado como una realidad a investigar; el análisis y cuestionamiento de las fuentes históricas, es decir extraer información directa de ellas y a la vez obtener datos a través de la indagación del contexto de la fuente trabajada; y, por último, relacionar informaciones generadas por el análisis de las fuentes y su contexto para desarrollar respuestas interpretativas (Sáiz, 2014).

Dentro del abanico de fuentes históricas que podemos trabajar para desarrollar el pensamiento histórico entre el alumnado encontramos la fotografía. Esta, en nuestra opinión, ha adquirido una gran relevancia en la sociedad actual en la que la imagen ha ganado un gran protagonismo como instrumento de comunicación. Esta realidad hace que resulte imprescindible que sea trabajada en el aula desde edades bien tempranas, ya que como señala Riego (2019) actualmente se vive en una sociedad con una abundancia de imágenes que sin embargo cada vez valoramos menos. En este sentido, Valls (2007) afirma que el desarrollo de la capacidad de crítica y análisis de las imágenes ha de ser uno de los objetivos de la educación escolar para contribuir a la formación del alumnado.

A este respecto el trabajo con una fuente histórica como la fotografía desde la enseñanzaaprendizaje de la Historia, y de las Ciencias Sociales en general, a partir de una metodología y estrategia adecuada, permite formar al alumnado en una doble vertiente. Por un lado, en su alfabetización visual, un concepto entendido en palabras de Avgerinou (2009) como las competencias que permiten realizar de forma crítica las acciones de leer, entender, utilizar y crear imágenes. Una definición que podría ser completada por la dada por Masterman, citado por Arqué (2002), quien respecto a la alfabetización audiovisual considera que se trata de relacionar los mensajes con los intereses políticos, sociales y económicos de sus emisores. Por otro lado, el segundo de los aspectos al que nos referimos es el desarrollo del pensamiento histórico por el cual el alumnado adquiera la capacidad y habilidad de tener una actitud crítica ante la realidad (Carretero y Montanero, 2008). Así pues, ambos aspectos guardan una estrecha relación pues como apunta Cooper (2015) la alfabetización visual, que puede ser trabajada desde edades tempranas, incide a su vez en el desarrollo del pensamiento histórico.

De hecho, como señalan Pagés y Santiesteban, la fotografía tiene una enorme potencialidad educativa intrínseca a sus propias características como documento gráfico y fuente histórica. Se trata de un vestigio del pasado voluntario que se realiza para dejar constancia de algo y que se crea, en un momento determinado, para ser memoria, al tiempo que es un instrumento que representa el sentimiento de conservación de la identidad y sustituye a la memoria oral entre las clases populares. Asimismo, permite las interpretaciones emotivas y subjetivas, al tiempo que requiere una decodificación global y un análisis que diferencie lo esencial y lo accesorio (Pagès y Santiesteban 2010). Siguiendo a estos mismos autores, la fotografía permite, por tanto, trabajar aspectos relacionados con el cambio y la continuidad, la causalidad histórica y la comparación en el tiempo.

Pero a pesar de todo lo expuesto anteriormente, consideramos que, a día de hoy, la fotografía no está lo suficientemente valorada desde un punto de vista didáctico para la enseñanza de la Historia en su consideración de fuente histórica, pese a que somos de la opinión que, más allá de su potencialidad educativa, cuenta con un cierto atractivo para el alumnado, quien no la percibiría como un medio extraño alejado de su realidad si tenemos en cuenta el volumen de imágenes que genera la sociedad en la que viven. En este sentido, el interés que puede generar entre el estudiantado 
consideramos que podría ser provocado por la capacidad de sugestión de la fotografía al imbuir al observador en el contexto que muestra la imagen (De las Heras, 2015), al tiempo que nos muestra hechos, situaciones y acontecimientos de una manera diferente que invita en palabras de Holzbrecher (2015, p. 385) "a descubrir e inventar historias", es decir, incita la curiosidad de quien fija su atención en ella. En esta misma línea, Rodríguez (2010) afirma que conseguir que el alumnado vea la fotografía como una pieza arqueológica lo predispone a un interés indagador que agudiza su atención y su observación sobre lo que le muestra.

Tal vez el origen de esta situación, del escaso aprovechamiento didáctico de la fotografía, se encuentre en el hecho de que, hasta no hace mucho, buena parte de los historiadores no concebían la imagen, y por tanto, la fotografía como una fuente histórica, al nivel por ejemplo de las fuentes textuales (Devoto, 2013), a causa de su carácter subjetivo y por ser susceptibles de generar diversas interpretaciones (Sanchidrian, 2011). Pero a día de hoy esta visión de la fotografía ha sido superada, pues como señala Pantoja (2010) la fotografía es una fuente útil para hacer memoria que ofrece nuevos planteamientos para el estudio de los procesos históricos. Sin embargo, más allá de su valor como fuente para comprender el pasado, la imagen, y por tanto la fotografía, cuenta con una serie de valores culturales y textuales que se han de interpretar a través de la apariencia visual (Riego 2010).

Respecto al tratamiento didáctico de la fotografía, y por extensión de la imagen, podemos señalar que su aprovechamiento es mínimo si atendemos a uno de los principales recursos utilizados en la enseñanza de la historia como son los libros de texto. En este ámbito son diversos los trabajos que se han centrado en el análisis de las imágenes que contienen los manuales escolares (Bel et al. 2019; Gámez-Ceruelo y Sáez-Rosenkranz, 2017; Valls, 1995 y 2007). Los análisis llevados a cabo ponen de manifiesto como en la mayoría de los casos las imágenes presentan un carácter meramente ilustrativo o decorativo (Bel et al., 2019; Valls, 2007) y son tratadas mayoritariamente a partir de actividades que presentan una complejidad cognitiva baja o simplemente se reducen a ser descritas (Bel et al. 2019). De este modo las imágenes recogidas en los manuales escolares no contribuyen a desarrollar entre el alumnado un aprendizaje complejo (Gámez Ceruelo, 2016; Gómez y López, 2014) y no son aprovechadas como fuentes históricas (Bel, 2018). A ello se ha de añadir que la fotografía tan solo representa un $16,5 \%$ del total de imágenes que incluyen los libros de texto, un porcentaje bajo a pesar de ocupar el segundo lugar por detrás del recurso más utilizado como son las obras pictóricas con un 44\% del total (Gómez y López, 2014).

Por ello la acción educativa que aquí se presenta tiene como objetivos mostrar una visión diferente de la mostrada mayoritariamente por los manuales escolares en relación a la potencialidad de la fotografía como recurso activo para la enseñanza-aprendizaje de la historia, partiendo de la hipótesis de que este tipo de fuentes pueden resultar atractivas y motivadoras para el alumnado e incitar al análisis y la reflexión sobre el pasado, dejando de lado, pues su carácter complementario y puramente ilustrativo para aparecer como un recurso de primer orden a través del cual no solo aprender contenidos, sino también procedimientos propios del método histórico y por tanto contribuir al desarrollo del pensamiento histórico del alumnado.

\section{Metodología}

La experiencia didáctica se llevó a cabo con un grupo de estudiantes de la asignatura de Didáctica de las Ciencias Sociales: Historia del grado de Educación Primaria de la Universidad de Alicante durante el curso 2018-2019. En total participaron 51 estudiantes, 11 hombres y 40, mujeres, de un total de 377 estudiantes que cursaron la asignatura. Se trata de una cifra baja, tan solo un 13,5\% en relación al total de alumnado, si bien se trató de una experiencia piloto para poder, posteriormente, trasladarla a todo el alumnado en cursos posteriores de la asignatura mencionada.

La actividad tenía como objetivo conocer las causas que provocaron la Guerra Civil española a partir del análisis de fuentes históricas como la fotografía. En este caso se optó por una estrategia indagatoria, ya que a través de ella el alumnado tienen la posibilidad de repensar el proceso de 
aprendizaje, de comprender qué sucede durante la adquisición del conocimiento (Hernández et al., 2011). Asimismo, en el caso de las ciencias sociales, la indagación permite el desarrollo de la competencia relacionada con el tratamiento de la información, al trabajar con fuentes (Gómez y Rodríguez, 2014). De hecho, como apunta Bermúdez (2015) este tipo de metodología o estrategia de tipo activo, la indagatoria, se encuentra estrechamente relacionada a menudo con el desarrollo del pensamiento crítico.

Dicho esto, los objetivos de esta experiencia, más allá de los relacionados con la adquisición de contenidos puramente históricos, eran por un lado mostrar una nueva manera de abordar el proceso de enseñanza-aprendizaje del pasado a través del análisis de fuentes históricas y la aproximación al método histórico. Asimismo, se buscaba contribuir a la alfabetización histórica y visual del futuro profesorado de Educación Primaria. Por último, se pretendía conocer la percepción de los participantes a cerca de la utilidad de la metodología para ser puesta en práctica en el aula durante su futuro profesional.

Como ya hemos mencionado anteriormente, la actividad se centró en conocer cuáles fueron las causas que dieron lugar a la Guerra Civil española, Por un lado, se establecieron seis causas estructurales: las tensiones sociales, el atraso económico, la reforma agraria, el problema regional, el problema religioso y la polarización política. Por otro lado, se fijaron tres causas coyunturales: La expansión del comunismo, el auge del nazismo y el fascismo y los efectos de la crisis de 1929. Se buscaba conocer si el alumnado era capaz de llegar a estas conclusiones a partir del análisis de fuentes o si su interpretación divergía una vez realizada la actividad.

El ejercicio se dividió en diversas fases. En la primera de ellas se pretendía valorar los conocimientos previos del alumnado sobre las causas que desencadenaron el conflicto bélico, tanto de carácter coyuntural como estructural, para lo cual debían indicar qué causas, tanto coyunturales como estructurales, consideraban que habían dado lugar a la Guerra Civil. Una vez realizado este ejercicio inicial se les facilitó un total de ocho fotografias (Tabla 1), y se les pidió que analizaran cada una de ellas y reflexionaran sobre las causas del conflicto. Cada una de las imágenes iba acompañada con un pie en el que constaban el autor, la fecha y el título de la obra. Estos datos les permitían situarse en el contexto e iniciar la búsqueda de información de cada una de las fotografías, para poder llevar a cabo el análisis y contraste de las mismas. En este sentido, hay que señalar que planteamos cinco imágenes para trabajar las causas estructurales y otras tres fotografías relacionadas con las causas coyunturales.

TABLA 1. Listado de fotografías utilizadas en la experiencia didáctica

Fotografía 1 Revuelta de campesinos delante del Parlament de Catalunya con motivo de la anulación de la ley de contratos de cultivo. Merletti, 1934. Barcelona. Colección Merletti/IEFC

Fotografía 2 Cadáveres amontonados tras la matanza de Casas Viejas. 1933.Hemeroteca/La Vanguardia

Fotografía 3

Asesinato de Calvo Sotelo. Alfonso Sánchez Portela.1936

Fotografía $4 \quad$ Francesc Macià proclama la República Catalana desde el balcón del Palau de la Generalitat de Catalunya. Merletti1931. Barcelona. Colección Merletti/IEFC

Fotografía 5 Incendio del templo de los Carmelitas en la plaza de España. Alfonso Sánchez Portela 1931 
Fotografía 6

El líder soviético Vladimir Lenin hablando a una multitud congregada el 7 de noviembre de 1918 durante el primer año de la Revolución en la Plaza Roja de Moscú. Colección AP.

Fotografía 7 Adolf Hitler lidera una unidad SA en un desfile de partido nazi en Weimar, 1931. United
States Holocaust Memorial Museum, courtesy of James Sanders

Fotografía $8 \quad$ Un grupo de personas se acumula a la salida de la Bolsa de Nueva York, el 24 de octubre de 1929, el Jueves Negro. Colección AP.

Fuente: elaboración propia

Tras el análisis de cada una de las imágenes, el alumnado debía buscar información, a través de obras bibliográficas y páginas de internet de contenido histórico, sobre las causas de la guerra y conectar cada una de las imágenes con aquellas que consideraran que tenían una mayor relación. Por último, habían de responder nuevamente al ejercicio inicial argumentando las causas de la Guerra Civil y expresando, esta vez, su opinión sobre la actividad y sus posibilidades de aplicación práctica en las aulas de primaria.

Toda la información obtenida a través de los cuestionarios propuestos se ha sistematizado con el propósito de conocer cuál ha sido su progresión en el proceso de aprendizaje, así como la valoración que hace el alumnado del trabajo con fuentes para la enseñanza de la Historia.

\section{RESUltadOS}

Los resultados de ambos cuestionarios han sido analizados a posteriori tanto desde el punto de vista cuantitativo, número de causas que eran capaces de citar, como cualitativo en relación con las fuentes utilizadas y el ejercicio desarrollado. Así pues, en lo que respecta al número de causas, tanto estructurales como coyunturales, citadas por el alumnado tanto antes de llevar a cabo la experiencia didáctica como después de haber realizado la misma (Gráficos 1 y 2) podemos observar una evolución positiva. En este sentido se buscaba conocer con detalle, cuántas causas concretas del conflicto podía mencionar. Los datos referidos al cuestionario previo a la acción educativa (Gráfico 1) nos muestran cómo solamente un 15,7 \% del alumnado fue capaz de mencionar tres o más causas estructurales, un porcentaje que también recoge la entrada "generalización", en donde el alumnado responde sin concretar ninguna de las causas. En esta misma línea, las respuestas relacionadas con las causas coyunturales (Gráfico 2) nos muestran que un $60 \%$ del alumnado no era capaz de mencionar ni una sola causa antes de desarrollar la acción educativa. Estas cifras mencionadas para ambos casos contrastan con los datos recogidos después de desarrollar la actividad. Así, en lo que respecta a las causas estructurales (Gráfico 1), un 82,5\% del alumnado fue capaz de citar de forma concreta tres o más causas, un porcentaje alto muy similar al de las respuestas dadas por el alumnado en relación a las razones coyunturales (Gráfico 2), ya que un $82,4 \%$ de los participantes fue capaz de citar las tres causas que se buscaban a través de la actividad. 
GRÁFICO 1. Número de causas estructurales citadas antes y despues de la actividad en \%

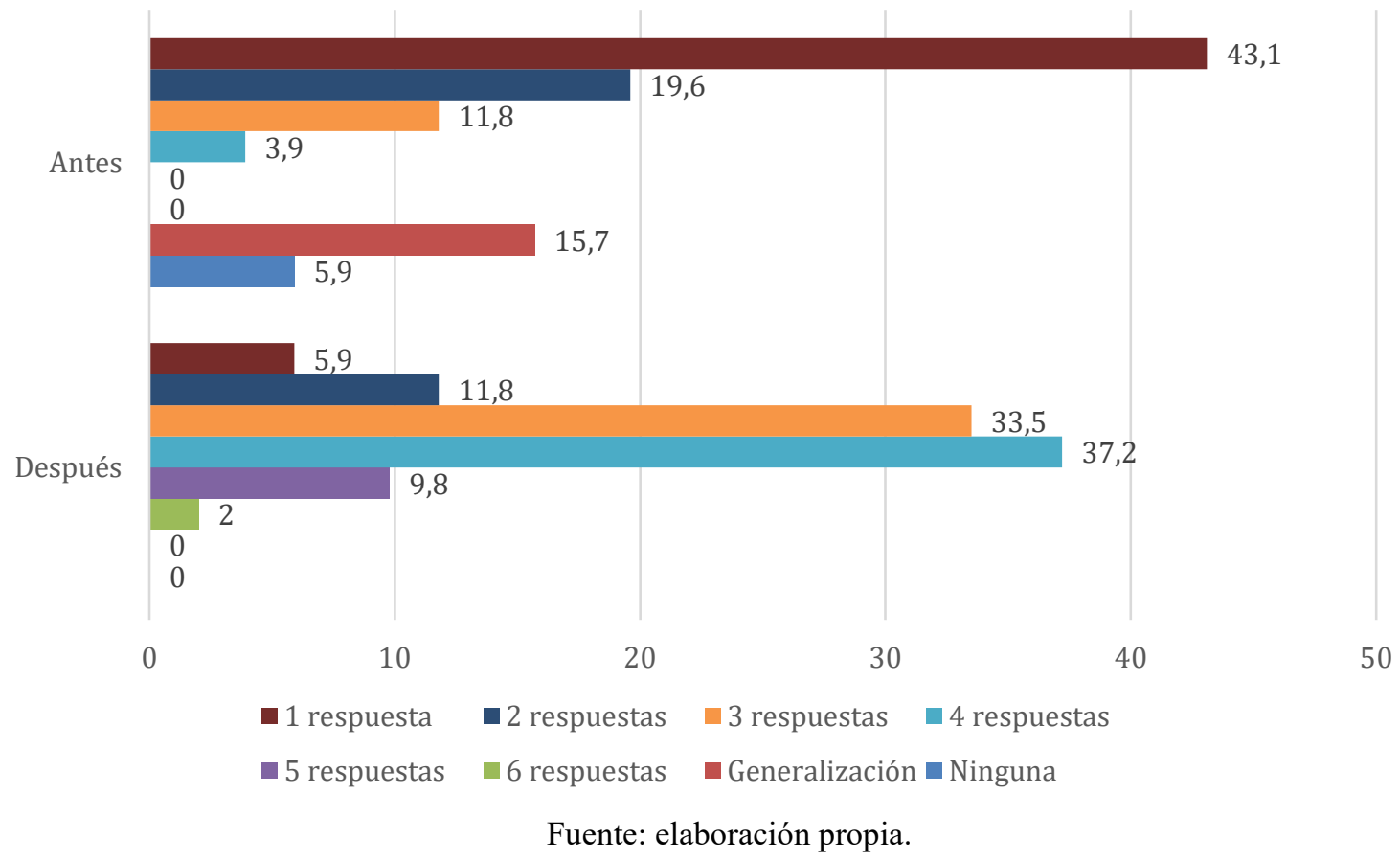

GRÁFICO 2. Número de causas coyunturales citadas antes y despues de la actividad en \%

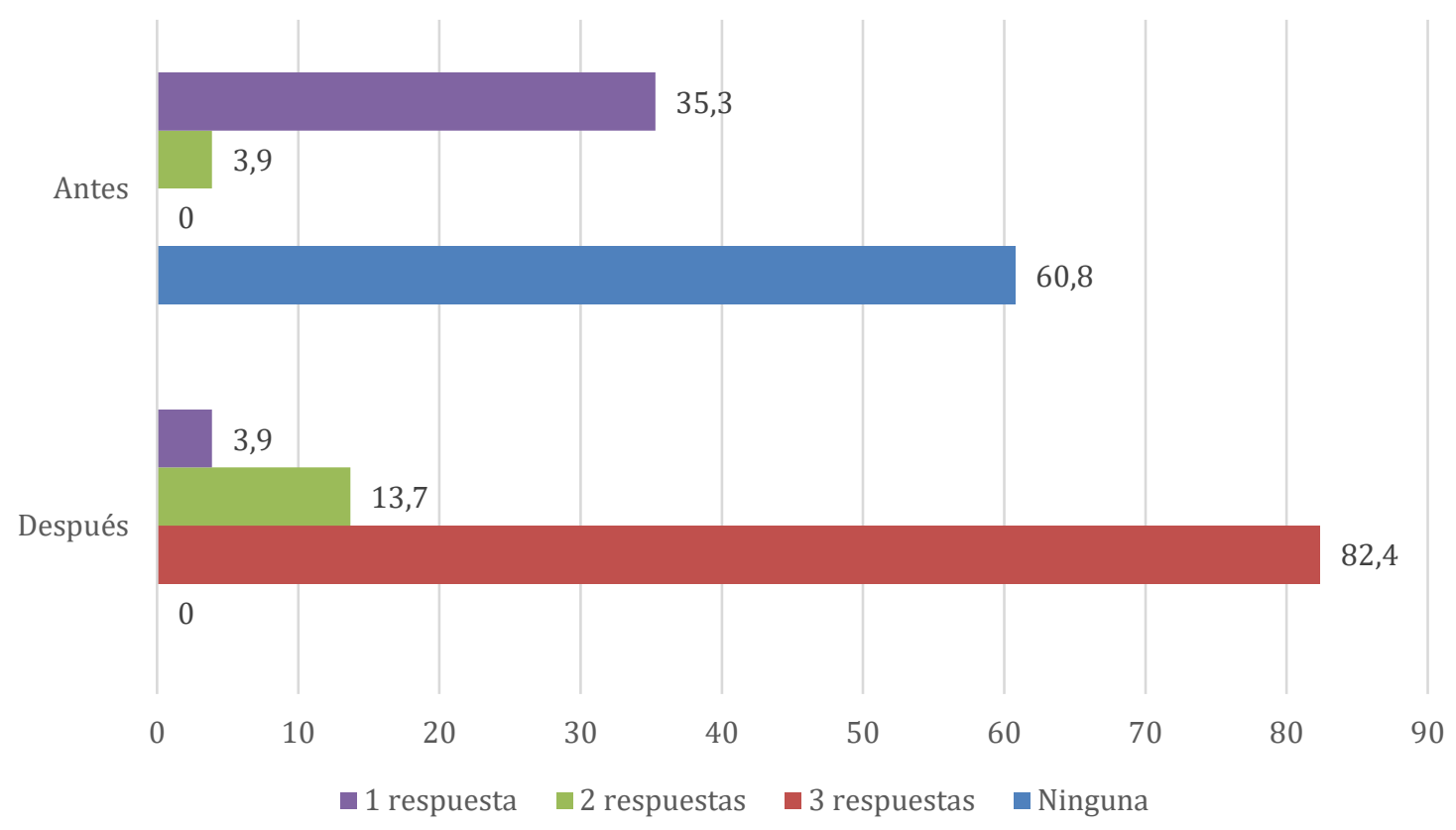

Fuente: elaboración propia

Respecto a cuáles fueron las causas concretas mencionadas por el alumnado los resultados relacionados con las causas estructurales quedan recogidos en el gráfico 3. Con anterioridad a la actividad desarrollada en clase podemos observar como la "polarización política" fue la causa más citada, ya que un 66,6 \% de los participantes la mencionaron. Tras ella el "atraso económico" ocupa el segundo lugar de las menciones con un 35,5\% de las respuestas. Por debajo de esta última causa, el resto no supera el $25 \%$ de las contestaciones, llamando la atención los casos del "problema 
religioso" y el "problema regional" con un $1,9 \%$ y un 3,9\% de las respuestas respectivamente. A estos datos cabría añadir que un $15,7 \%$ del alumnado no fue capaz de concretar ninguna de las causas estructurales. Frente a estos resultados, las respuestas ofrecidas por los participantes después de desarrollar la actividad nos muestran otra realidad. Así pues, la causa menos mencionada, la "reforma agraria" y el "atraso económico", alcanzan un $42,5 \%$ y un $48,9 \%$ respectivamente, mientras que el resto de causas superan el 50\% de las respuestas destacando con un 87,2 la "polarización política" y con un 72,3 "las tensiones sociales". Citar por último que tan solo un 2,1\% de los participantes no fue capaz de concretar ni una sola causa estructural después de desarrollar la actividad.

GRÁFICO 3. Causas estructurales especificadas antes y después de la actividad (en \%)

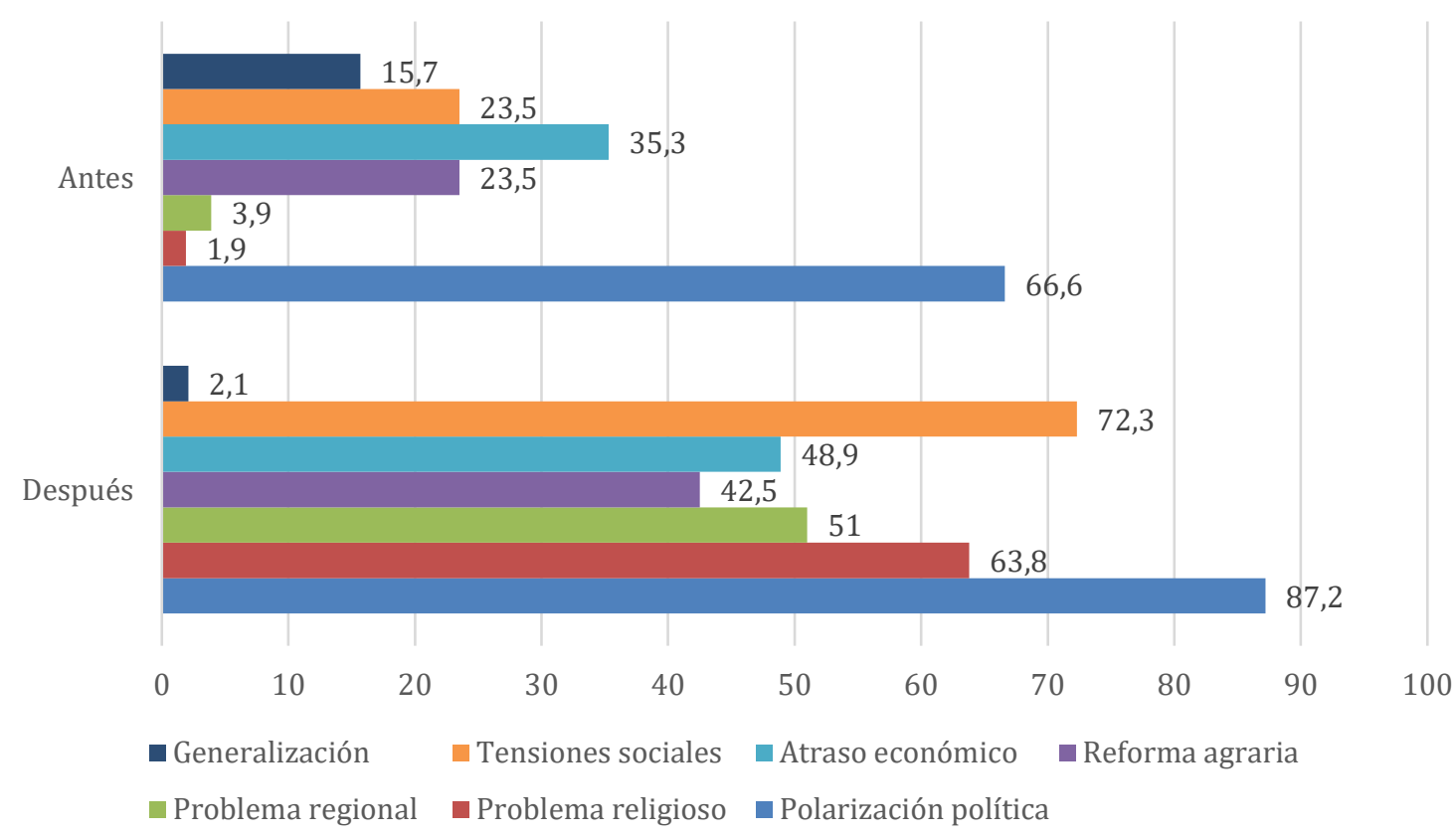

Fuente: elaboración propia

GRÁFICO 4. Causas coyunturales especificadas antes y después de la actividad (en \%)

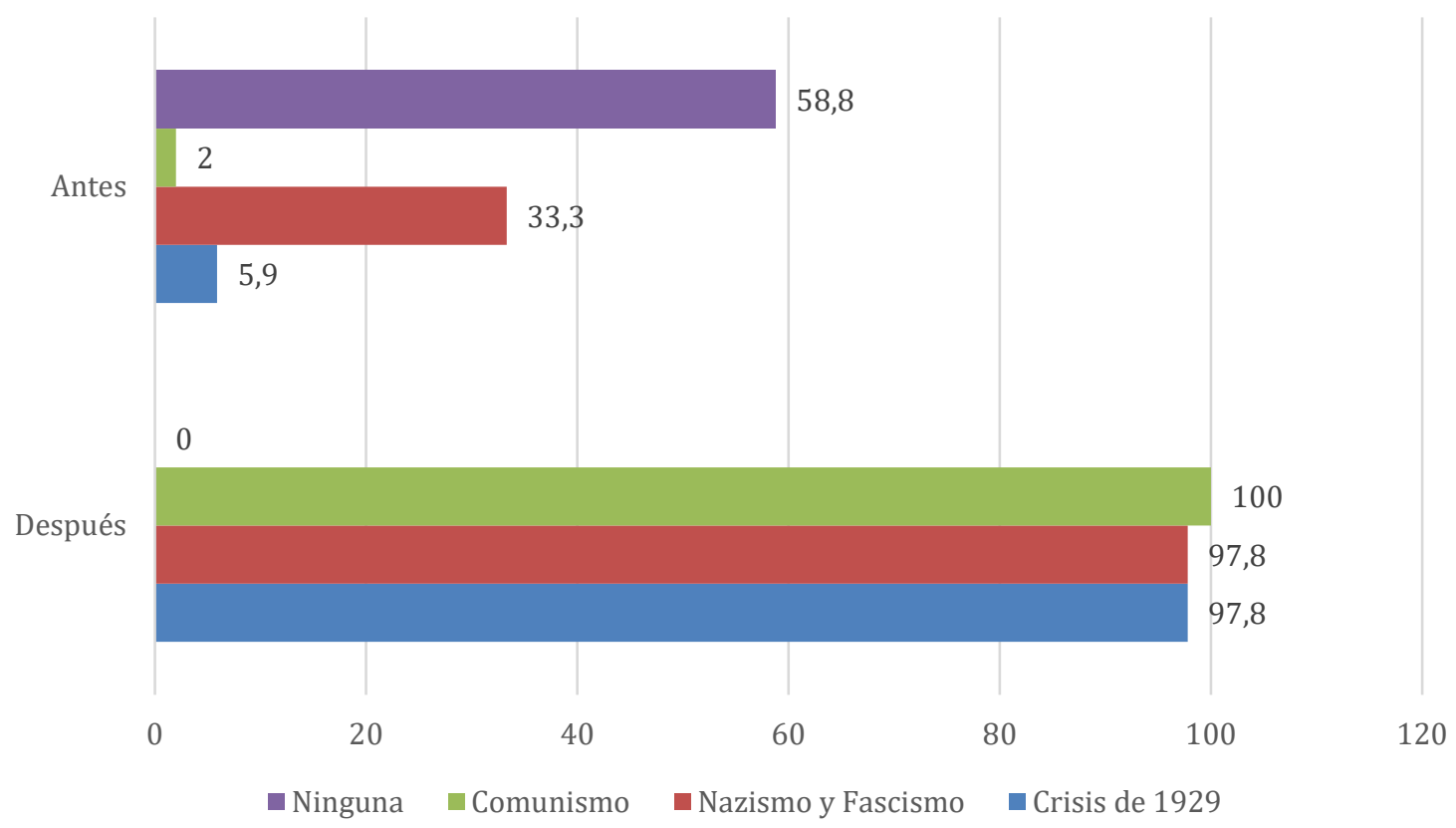

Fuente: elaboración propia 
Los datos relacionados con las causas coyunturales quedan recogidos en la gráfica 4 , en donde se puede apreciar la evolución de las respuestas del alumnado participante antes y después de la experiencia didáctica. En este sentido un 58,8\% de los participantes no citaron ninguna de las causas coyunturales del conflicto y únicamente un 33, 3\% mencionó la relacionada con el "auge del nazismo y el fascismo", mientras que la "expansión del comunismo" solo es señalada por un 5,9\% del alumnado. Los resultados posteriores muestran como a partir del ejercicio prácticamente todo el alumnado fue capaz de reconocer las causas coyunturales que les mostraban las fuentes trabajadas.

Realizada la experiencia didáctica el alumnado participante fue preguntado por la utilidad de la actividad y si consideraban apropiada este tipo de acciones para aplicarlas durante su futuro profesional en la formación del alumnado de primaria. Respecto a la primera cuestión un $97 \%$ del alumnado considero útil esta manera de trabajar la Historia. Del mismo modo, otro $97 \%$ de los participantes consideró que se trataba de una actividad aplicable con estudiantes de la etapa de Primaria. Si bien en este último caso, al tratarse de una respuesta abierta, alegaban diferentes razones o motivaciones tal y como se puede apreciar en el gráfico 5. En este sentido, entre los argumentos más mencionados podemos señalar que un $24,7 \%$ de los participantes considera que este tipo de acciones educativas permite el análisis, la reflexión y la asimilación de los contenidos y procedimientos de la historia. La segunda de las razones más citadas, con un $22,2 \%$ de las respuestas, consideraba que se trataba de una forma de trabajar activa, mientras que un 14,8\% de los participantes la llevarían al aula por su alto contenido motivador. Asimismo, un 12,4\% de las respuestas manifestaban que a través de esta manera de enseñar se acerca la historia al alumnado, la hace más próxima al estudiante, mientras que un $9 \%$ incidía en el carácter innovador de la propuesta.

GRÁFICO 5. Motivos por los que el alumnado aplicaría este tipo de actividades en un aula de primaria (en \%)

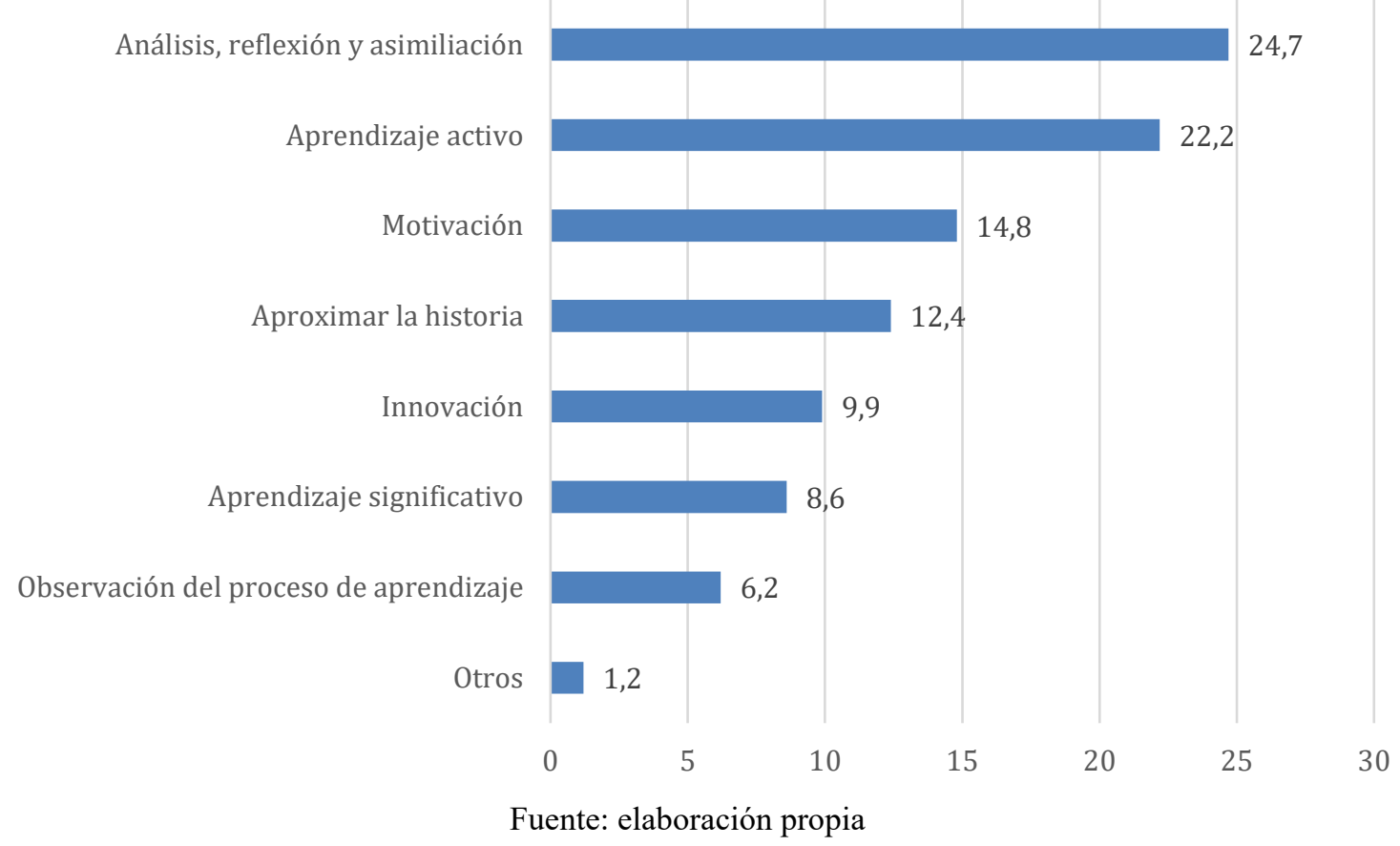

\section{Conclusiones}

El trabajo con fuentes históricas en el aula de primaria tiene un enorme potencial a la hora de la enseñanza de la historia. Pero para un total aprovechamiento didáctico de este recurso se requiere llevar a cabo un proceso de formación del futuro profesorado, cuya preparación en el uso de las fuentes históricas durante sus estudios previos podemos calificar de escasa. En este sentido, si 
tenemos en cuenta que la utilización de libros de texto ha sido mayoritaria en la formación histórica previa del futuro profesorado de educación primaria, compartimos las conclusiones de J. Sáiz, en su estudio sobre el uso de fuentes históricas en los libros de texto de secundaria, en relación a la inexistencia ni de una alfabetización histórica del alumnado ni tampoco de una enseñanza de las competencias o destrezas relacionadas con el desarrollo del pensamiento histórico (Sáiz, 2014). En esta línea hemos de tener en cuenta que resulta muy complicado poder trabajar con el alumnado el método histórico, si el profesorado carece de formación en este sentido (Prats, 1996). Por ello es necesaria una preparación, que capacite al futuro maestro o maestra, no para ejercer de historiadores, sino para utilizar las principales metodologías para trabajar la Historia y de esta manera seleccionar las fuentes en función de la finalidad educativa que se desea conseguir (Borghi, 2010). Pero para ello, en primer lugar, han de comprobar los beneficios de aplicar esta forma de trabajar en el aula, para de este modo desarrollar competencias metodológicas y pedagógicas que sean susceptibles de ponerse en práctica posteriormente en sus clases (Inarejos, 2017)

En este sentido, a la luz de los datos obtenidos de la acción educativa que hemos tratado en el presente artículo, podemos observar cómo se produce un aprendizaje por parte del alumnado a través de una estrategia indagatoria que utiliza las fuentes históricas y se adentra en el uso del método historiográfico. Así pues, la actividad está en relación con las tres destrezas básicas, señaladas por Sáiz (2014), a la hora de trabajar con fuentes históricas: el planteamiento de un problema de aprendizaje histórico, el análisis de fuentes históricas para construir pruebas del pasado y el desarrollo de respuestas interpretativas. Si bien, en relación a este último aspecto cabría hacer una reconsideración para acciones futuras, incidiendo aún más en el carácter narrativo y argumentativo, más allá de la simple exposición de conclusiones.

Consideramos que la actividad ha cumplido los objetivos descritos líneas arriba, así buena parte del alumnado manifiesta cómo este tipo de actividad con fuentes históricas permite el análisis y la reflexión sobre el hecho histórico tratado, más allá de una simple memorización, lo cual se relaciona con lo señalado hace ya más de un siglo por Wesley (1916) quien consideraba que trabajar con fuentes es fundamental para enseñar al alumnado a pensar. Asimismo, los resultados muestran que los participantes relacionan esta estrategia de enseñanza con las metodologías activas que permiten el análisis y la reflexión y, a su vez, con una vertiente motivadora de tratar la historia, lo que relaciona este tipo de actividad con aquellas metodologías que se alejan de la tradicional, de corte expositivo y memorístico. Como señala una de las alumnas esta actividad "acerca la historia" gracias a la fotografía, un aspecto que subraya la idea de De las Heras (2015) cuando afirma la gran utilidad que tiene este recurso para la construcción de la historia al tratarse de una fuente de memoria que permite una aproximación al pasado y que, sin duda, como apuntan Santiesteban, González y Pagès (2010, p.120) "pone en contacto directo al alumnado con el pasado". Por tanto, la visualización del pasado como algo más próximo ayuda a su comprensión y en consecuencia a la motivación del alumnado ante el aprendizaje de la historia, ya que de alguna manera se siente partícipe de su construcción.

Así pues, podemos finalizar señalando que la enseñanza del método histórico entre el alumnado permite, más allá del tratamiento de un tema en concreto, que vean cómo la historia incita a la reflexión, a alcanzar un pensamiento analítico y crítico (San Pedro, 2013), de una manera activa y significativa. Un objetivo que nos planteábamos al inicio de esta actividad y que, a la luz de los resultados obtenidos, y de la opinión de los participantes, consideramos que se ha cumplido en gran medida, al tiempo que se ha corroborado la hipótesis del atractivo que ejerce la imagen fotográfica para el alumnado y de su carácter motivador. Por tanto, consideramos que este tipo de actividades contribuye a superar una de las principales dificultades del proceso de enseñanza-aprendizaje de la Historia como es la concepción del alumnado de la materia histórica al reconocer los rasgos de la Historia como ciencia y dejar de considerarla como una materia que no ha de ser comprendida sino simplemente memorizada (Prats, 2017). 


\section{Referencias}

Arqué, M. (2002). Las fuentes documentales fotográficas en la Didáctica de las Ciencias Sociales. En P. Amador, J. Robledano y M. R. Ruiz (Eds.) Primeras Jornadas Imagen, Cultura y Tecnología (pp. 275-283). Madrid: Universidad Carlos III, Editorial Archiviana.

Avgerinou, M.D. (2009). Re-Viewing Visual Literacy in the «Bain d'Images» Era. TechTrends, 53, 28-34. DOI: $10.1007 / \mathrm{s} 11528-009-0264-\mathrm{z}$

Bel, J. C. (2018). El uso intertextual de las fuentes históricas icónicas en los manuales escolares de la LOMCE. Didacticae. Revista de investigación en didácticas específicas, 4, 25-41. DOI: 10.1344/did.2018.4.25-41.

Bel, J.C., Colomer, J.C. y Valls, R. (2019). Alfabetización visual y desarrollo del pensamiento histórico: actividades con imágenes en manuales escolares. Educación XX1, 22(1), 353-374, DOI: $10.5944 /$ educXX1.20008

Bermúdez, A. (2015). Four Tools for Critical Inquiry in History and Civic Education. Revista de Estudios Sociales, 52, 102-118. DOI: 10.7440/res52.2015.07

Borghi, B. (2010). Las fuentes de la historia entre investigación y didáctica. En R.M. Ávila, P. Rivero y P.L. Domínguez (Coords.) Metodología de investigación en Didáctica de las Ciencias Sociales (pp. 74-85). Zaragoza: Institución "Fernando el Católico" (CSIC)-Asociación Universitaria de Profesorado de Didáctica de las Ciencias Sociales.

Calvani, A. (1999) Il bambino, il tempo e la storia. Florencia: Nuovaltalia

Carretero, M. y Montanero, M. (2008). Enseñanza y aprendizaje de la Historia: aspectos cognitivos y culturales. Cultura y educación, 20(2), 133-142. DOI: 10.1174/113564008784490361

Cooper. H. (2015). How can we plan for progression in Primary School History? Revista de Estudios Sociales, 52, 16-31. DOI: 10.7440/res52.2015.02

De las Heras, B. (2015) Testimoniando con imágenes. La fotografía en el estudio de la historia. Fotocinema, 10, 27-55. DOI: 10.24310/Fotocinema.2015.v0i10.5978

Devoto, E.A. (2013). La imagen como documento histórico-didàctico: algunas reflexiones a partir de la fotografía. Revista de Educación (Argentina), 6, 73-94. Recuperado de https://fh.mdp.edu.ar/revistas/index.php/r_educ/article/view/753/770

Egea, A. y Arias, L. (2015). La arqueología llega a las aulas. Objetos y otras fuentes primarias para la enseñanza de la historia. En G. Solé (coord.), Educação Patrimonial: contributos para a construção de uma consciência histórica (pp. 151-169). Braga: Centro de Investigação em Educação (CIEd) - Instituto de Educação, Universidade do Minho.

Fuentes, C. (2003). ¿Qué visión tiene el alumnado de la historia como campo de conocimiento y como materia escolar? Íber: Didáctica de las Ciencias Sociales, Geografía e Historia, 36, 7888.

Gámez-Ceruelo, V. (2016) La función educativa de la imagen en el área de Ciencias Sociales de Educación Primaria. Un estudio exploratorio en torno al currículo escolar, los libros de texto y la concepción del alumnado del Grado de Maestro de Educación Primaria. (Tesis doctoral) Universitat de Barcelona. Recuperado de http://hdl.handle.net/2445/104188

Gámez-Ceruelo, V. y Sáez-Rosenkranz, I. (2017). La imagen como documento gráfico visual en la enseñanza de la historia en Educación Primaria en perspectiva comparada. Análisis y propuesta didáctica. Revista Electrónica Interuniversitaria de Formación del Profesorado, 20(2), 127142. DOI: $10.6018 /$ reifop/20.2.284781

Gómez, C. J. y López, A. (2014). Las imágenes de los libros de texto y su función en la enseñanza de la historia. Diseño de un instrumento de análisis. Enseñanza de las Ciencias Sociales, 13, 17-29. DOI: 10.1344/ECCSS2014.13.2

Gómez, C. J.; Ortuño, J. y Molina, S. (2014). Aprender a pensar históricamente. Retos para la historia en el siglo XXI. Tempo e Argumento, 6(11), 1-25. DOI: 10.5965/2175180306112014 
Gómez, C. J. y Rodríguez, R. A. (2014). Aprender a enseñar Ciencias Sociales con métodos de indagación. Los estudios de caso en la formación del profesorado. REDU. Revista de docencia universitaria, 12(2), 307-325. DOI: 10.4995/redu.2014.5651

Hernández, X. (2002). Didáctica de las Ciencias Sociales, Geografía e Historia. Barcelona: Graó.

Hernández, F. X. y Cardona, G. (2015). La historia en primaria. Problemas y perspectivas. Revista Aula de Innovación Educativa, 240, 12-17.

Hernández, F., Forés, A., Sancho, J.M., Sánchez, J.A., Casasblancas, S., Creus, A., Herráiz, F. y Padró, C. (2011). Aprender desde la indagación en la universidad. Barcelona: Octaedro-ICE Universitat de Barcelona.

Holzbrecher, A. (2015). La fotografía en la educación mediática: su papel en la labor (extra) académica. Profesorado. Revista de Currículum y Formación de Profesorado, 19(1), 380-394. Recuperado de https://www.ugr.es/ recfpro/rev191COL6.pdf

Inarejos, J. A. (2017). El uso de fuentes históricas y bases documentales en la formación del profesorado de Educación Infantil y Primaria Revista electrónica interuniversitaria de formación del profesorado, 20(2), 157-166. DOI: 10.6018/reifop.20.1.289901

Llonch-Molina, N. y Parisi-Moreno, V. (2018). Experiencia didáctica para la enseñanza de la historia contemporánea a través de las fuentes en Educación Superior. Panta Rei. Revista Digital de Ciencia y Didáctica de la Historia, 161-176. DOI:10.6018/2018/8

Miralles, P., Gómez, C.J. y Monteagudo, J. (2012). La evaluación de la competencia social y ciudadana en ciencias sociales al finalizar las etapas de Primaria y Secundaria. Investigación en la escuela, 78, 19-30. DOI: 10.12795/IE.2012.178.02

Ortega, D., Carcedo, B. P. y Blanco, P. (2018). Enseñar a interpretar históricamente en Educación Primaria: representaciones del profesorado en formación sobre el manejo de fuentes históricas en la enseñanza de la Historia. En E. López, C. R. García y M. Sánchez (Eds.) Buscando formas de enseñar: Investigar para innovar en Didácticas de las Ciencias Sociales (pp. 33-45). Valladolid: Asociación Universitaria de Profesorado de Didáctica de las Ciencias SocialesUniversidad de Valladolid.

Pagès, J. y Santiesteban, A. (2010). La enseñanza y el aprendizaje del tiempo histórico. Caderno Cedes, 82(30), 281-309. Recuperado de http://www.cedes.unicamp.br

Pantoja, A. (2010). La fotografía como recurso para la didáctica de la Historia., Tejuelo, 9,179-194. Recuperado de https://mascvuex.unex.es/revistas/index.php/tejuelo/issue/view/159

Peck, C. y Seixas, P. (2008) Benchmarks of Historical thinking: first steps. Canadian Journal of Education, 31(4), 1015-1038. DOI: 10.2307/20466737

Prats, J. (1996). El estudio de la historia local como opción didáctica. ¿Destruir o explicar la historia? Íber. Didáctica de las Ciencias Sociales, Geografía. e Historia, 8, 93-106.

Prats, J. (2007) La Historia es cada vez más necesaria para formar personas con criterio. Escuela, 37 , 22-23.

Prats, J. (2017). Retos y dificultades para la enseñanza de la Historia. En P. Sanz, J. M., Molero, y D. Rodríguez, D. (eds.), La historia en el aula. Innovación docente y enseñanza de la historia en la educación secundaria (pp. 15-32). Lleida: Milenio

Prats, J. y Santacana, J. (2015). Nous paradigmes en l'ensenyament de la historia. New paradigms in teaching history. Educació i História: Revista d'Història de l'Educació, 26, 19-39. DOI: $10.2436 / 20.3009 .01 .151$

Prieto, J. A., Gómez, C. J. y Miralles, P. (2013). El uso de fuentes primarias en el aula y el desarrollo del pensamiento histórico y social. Una experiencia en Bachillerato. Clio: History and History Teaching, $39 . \quad$ Recuperado de http://clio.rediris.es/n39/articulos/historiasocial/PrietoGomezMiralles.pdf

Riego B. (2010). Mirant la història i aprenent a experimentar amb nous mètodes. Educació $i$ Història. Revista d'Historia de l'Educació, 15,19-39. DOI: 10.2436/20.3009.01.52 
Riego, B. (2019). Las imágenes como fenómeno cultural: una necesaria mirada en etapas para abordar los retos culturales. Historia y Memoria de la Educación, 10, 17-49. DOI: $10.5944 / \mathrm{hme} \cdot 10.2019 .22348$

Rodríguez de las Heras, A. (2010). L'ús pedagògic de la fotografia histórica. Educació i Història: Revista d'Història de l'Educació, 15, 41-54. DOI: 10.2436/20.3009.01.53

Sáiz, J. (2013). Alfabetización histórica y competencias básicas en libros de texto de historia y aprendizajes de estudiantes. Didáctica de las ciencias experimentales y sociales, 27, 43-66. DOI: 10.7203/DCES.27.2648.

Sáiz, J. (2014). Fuentes históricas y libros de texto en secundaria: una oportunidad perdida para enseñar competencias de pensamiento histórico. Ensayos. Revista de la Facultad de Educación de Albacete, 29-1, 83-99. DOI: 10.18239/ensayos.v29i1.503

Sáiz, J. y Domínguez, J. (2017) Aprender sobre la historia: competencias metodológicas en la educación secundaria. En R. López, P. Miralles, J. Prats (dirs.) y C. J. Gómez (coord.) Enseñanza de la historia y competencias educativas (pp. 23-48), Barcelona: Graó.

San Pedro M.B. (2013). La introducción del método histórico en el alumnado del grado de Educación Primaria: reconstruyendo una aldea medieval. En J. Pagès y A. Santiesteban (eds.) Una mirada al pasado y un proyecto de futuro. Investigación e innovación en didáctica de las ciencias sociales, vol. 2 (pp. 505-513) Barcelona: Asociación Universitaria de Profesorado de Didáctica de las Ciencias Sociales-Universitat Autònoma de Barcelona.

Sanchidrián, Carmen (2011). El uso de imágenes en la investigación histórico-educativa. Revista de Investigación Educativa, 29(2), 295-309. Recuperado de https://revistas.um.es/rie/issue/view/10281

Santisteban, A. (2010). La formación en competencias de pensamiento histórico. Clío \& Asociados, 14, 34-56. DOI: https://doi.org/10.14409/cya.v1i14

Santisteban, A., González-Monfort, N. y Pagés, J. (2010). Una investigación sobre la formación del pensamiento histórico. En R. Ávila, P. Rivero y P. Domínguez, (coords.) Metodología en investigación en didáctica de las ciencias sociales (pp. 115-128). Zaragoza: Institución Fernando el Católico-Asociación Universitaria de Profesorado de Didáctica de las Ciencias Sociales.

Seixas, P. y Morton, T. (2013) The big six historical thinking concepts. Toronto: Nelson.

Feliu, M. y Sallés, N. (2011). El método científico para enseñar Historia: una experiencia en la formación de maestros. Clío: History and History Teaching, 37. Recuperado de http://clio.rediris.es/n37/articulos/FeliuySalles2011.pdf

Valls, R. (1995). Las imágenes en los manuales escolares españoles de Historia. Una propuesta de análisis y valoración crítica de los mismo desde criterios didácticos-historiográficos. Íber. Didáctica de las Ciencias Sociales, Geografía e Historia, 17, 69-78

Valls, R. (2007) Las imágenes en los manuales escolares de Historia y las dificultades de su uso didáctico. Clío \& Asociados: la historia enseñada, 11, 11-23. DOI: https://doi.org/10.14409/cya.v1i11.1625

Wesley, Ch. (1916) The problem of sources and methods in history teaching. The school review a Journal of secondary education, 24(5), 329-341. Recuperado de http://www.jstor.org/stable/1077912.

Wineburg, S. S. (2001). Historical thinking and other unnatural acts: charting the future ofteaching the past. Philadelphia: Temple University Press.

CÓMO CITAR ESTE ARTÍCULO

Ponsoda López de Atalaya, S. y Blanes Mora, R. (2020). La fotografía como fuente histórica en el aula. Análisis de una metodología para la enseñanza de la Historia en la Educación Superior. Didáctica de las ciencias experimentales y sociales, 39, 17-30. DOI: 10.7203/DCES.39.16078 
